Strength in Signals:

Tying Hands and Sunk Costs in Military Coercion

\author{
Abigail Post \\ Charlottesville, VA
}

B.A, Political Science, International Studies, The College at Brockport, SUNY, 2011

\begin{abstract}
A Thesis presented to the Graduate Faculty of the University of Virginia in Candidacy for the Degree of Master of Arts
\end{abstract}

Department of Politics

University of Virginia

May 2014 


\title{
Strength in Signals: Tying Hands and Sunk Costs in Military Coercion
}

\author{
Abigail S. Post
}

May 2014

\begin{abstract}
What makes a state's threats more credible? That is, how can states demonstrate their resolve in a crisis? This paper employs new data to determine whether different tools of military force are more effective at demonstrating resolve in a crisis. The dataset decomposes demonstrations of force into land, naval, and air signals and subsequently evaluates their respective usage by states to bolster coercive threats. This paper evaluates how demonstrations of force with different levels of sunk costs and tying hands affect crisis outcomes. It finds that increasing levels of sunk costs do not affect crisis outcomes; rather, the mere presence of a tying hands element increases the level of target compliance. This study goes further than the current literature on costly signals in establishing that not only do demonstrations of force enhance threat credibility but also that different military demonstrations are equally effective in achieving crisis outcomes.
\end{abstract}




\section{Introduction}

Having already chosen to enter a crisis, what is the best way for a state to achieve concessions short of war? Fearon's (1997) theoretical results point to the prediction that a state should do better with a tying-hands signal than a sunk costs signal, even though the lock-in results of the tying-hands signal also increase the probability of war. However, he only speculates as to what occurs when a signal both ties hands and sinks costs. This paper seeks to delineate how a combination of these two types in military signals can have counterintuitive results on the bargaining process. Are tying hands, sunk costs, or a combination of sorts more effective at producing bargaining success? The following case study will drive the central puzzle of this paper, demonstrating the importance of this question and illuminating the options available to states in crisis bargaining situations.

After the Arab spring and the Syrian uprising in March 2011, President Obama waited five months to call for Syrian President Assad's removed on August 11. In August 2012, asked about reports that Syria may be prepared to use chemical weapons against rebels, U.S. President Obama said: "We have been very clear to the [Bashar Assad] regime, but also to other players on the ground, that a red line for us is we start seeing a whole bunch of chemical weapons moving around or being utilized. That would change my calculus. That would change my equation" (Jackson 2013, Betts 2013). Although this statement was unplanned, President Obama set himself up to incur audience costs - both domestic but especially international - should he fail to follow through on this statement. A year later, on August 21, 2013, rumors eventually confirmed as true reports spread that the Syrian regime had killed hundreds in a poison-gas attack in eastern Damascus ("Syria Crisis"). However, the U.S. chose not to intervene. The President's statement did not tie his hands, and his decision to not intervene in Syria was a relief to the American public.

Even before the chemical weapons attack, the U.S. contemplated the use of force and provided humanitarian assistance and some rumored covert assistance. The U.S. Committee on Foreign Affairs met to discuss potential solutions to the Syrian crisis, "Reports yesterday 
indicate the United States will send a Patriot missile batter and F-16 fighters to Jordan for a drill and may keep them there. We have already stationed a patriot battery in southern Turkey" ("A Crisis Mismanaged":3). Many advocated a no-fly zone as accomplished in Libya 2011. However, after the chemical attack, the U.S. took a cautious route. "Pentagon officials told NBC News that Navy destroyers, plus two American and one British submarine, were in position in the Mediterranean Sea and ready to launch Tomahawk missiles if Obama gives the order. A fifth Navy destroyer has entered the Mediterranean on a scheduled swap with one of the four other destroyers but is not expected to take part in the missile strikes" (Miklasqewski et al. 2013). The U.S. could have introduced the contemplated no-fly zone, mobilized their military after the "red line" was crossed, or deployed a larger naval fleet in combination with a clear military threat. Despite its earlier public announcement and some flexible amphibious forces, the U.S. demonstrated its reluctance to get militarily involved in the Syrian Crisis.

Still, according to most theories of costly signaling, the U.S. should have succeeded in this crisis for two reasons. First, President Obama's public statement drawing a red line and setting himself up for audience costs - should have been credible enough to the Syrian government that they would not have tested the waters of U.S. resolve. However, this tying hands strategy did not work out the way that the audience costs literature, especially an ideal-type Fearon argument, would predict. Second, U.S. limited deployment of Naval force to the Mediterranean should have corroborated U.S. threats as a sunk costs signal. However, this limited demonstration of force did not add leverage to U.S. resolve. This situation poses a puzzle: What could the U.S. have done to better demonstrate its resolve? Would a more costly (in monetary terms) signal have been more effective? The thrust of this case study is that perhaps not all costly signals are the same, although they are depicted as relatively homogenous in many models on crisis bargaining.

This paper proposes a theory of costly signaling that goes beyond the narrow distinction between tying hands and sunk costs so predominant in the literature. Rather than a state 
choosing between sinking costs and tying hands, states must choose from a continuum of costly signals that communicate resolve. States can employ a variety of signals with different types of tying hands elements and varying levels of sunk costs. This paper will proceed as follows. First it will explore the extant theories of costly signaling in the literature to understand the costs that a state can incur to demonstrate resolve. Second, it develops three testable hypotheses from these theories. Third, it employs new data that decomposes military signals into land, naval, and air signals and subsequently evaluates their respective usage by states to bolster coercive threats. Fourth and last, it discusses the implications of the findings and potential paths for future research.

\section{Theoretical Underpinnings}

What makes a state's threats more credible? That is, how can states demonstrate their resolve, i.e. their willingness to use force, in a crisis? Due to private information about capabilities and resolve and incentives to misrepresent such information, states seek pathways to signal their true resolve or overrepresent their resolve in a crisis (Fearon 1995). Making a threat credible "requires having those intentions, even deliberately acquiring them, and communicating them persuasively to make other countries behave" (Schelling 1966:36). Fearon (1992) argues that states try to solve this dilemma by employing costly signals, in which the signaler incurs costs or risks that a (potentially) unresolved state would be averse to. ${ }^{1}$ This paper focuses on the effectiveness of military signals in bolstering coercive threats. I adapt Slantchev's (2011:66) definition of a military threat (i.e. signal) as "any physical move that satisfie[s] the following two criteria: 1) it is inherently costly and 2) it changes the distribution of power during the crisis." Military signals are a subset of costly signals, for states can employ costly non-military means of communication.

The primary theoretical issue this paper grapples with is distinguishing between Fearon's (1997) two ideal types of costly signals in the context of military threats: tying hands and

\footnotetext{
${ }^{1}$ See also Schelling (1966), Jervis (1970), Glaser (1994/95), Kydd (2005).
} 
sunk costs. States can make their threats more credible by tying hands signals, which are $e x$ ante costs incurred only if the state backs down in a crisis. ${ }^{2}$ Hand-tying signals manipulate the sender's future payoffs by increasing the costs of backing down and subsequently making conflict more attractive. ${ }^{3}$ This signal is not costly up front, but rather the sender pays the cost only if it does not follow through on its commitment. ${ }^{4}$ On the other hand, sunk costs signals are actions that are ex ante costs paid up front that do not change the decision-making calculus for future actions. It typically takes the form of "burning money" to demonstrate how much a state values the issue at hand; these types of signals need to take an all or nothing stance, because if the size of the signal is large in absolute terms, what matters is that it be large according to the military power of the state and the political issue at stake. ${ }^{5}$

Fearon admits that these are ideal types. A purely ex ante costless signal is possible - here he is focusing on a leader's public statement with no other actions - but it is more difficult to imagine a purely sunk costs signal for the following reason: "Building arms or mobilizing troops entails costs no matter what the outcome, but they also may affect the states expected value for fighting versus acquiescing in a challenge (which may have something like a tying hands effect)" (Fearon 1997:70). It is clear that most military demonstrations of force have the ability to simultaneously incur both ex ante and ex post costs. For one, they sink costs in that they are expensive to deploy. On the other hand, in order to be an effective signal, they must be highly public and therefore increase audience costs. Slantchev (2005) argues that military mobilization sinks costs and contributes positively to the probability of victory in a dispute and thus increases the expected utility of war. Hence, he concludes that military

\footnotetext{
${ }^{2}$ See Schelling (1960;27-28).

${ }^{3}$ Slantchev (2011) categorizes tying hands as separate from costly signaling. This strategy rearranges incentives to commit while costly signals communicate preexisting information.

${ }^{4}$ This idea is popular in the audience costs literature. See Fearon (1994), Fearon (1997), Tomz (2007), Snyder and Borghard (2011), Downs and Sechser (2012), Trachtenberg (2012), Potter and Baum (2014). Audience costs "arise from the action of the domestic audiences concerned with whether the leadership is successful or unsuccessful at foreign policy" (Fearon 1994a:577).

${ }^{5}$ Jervis (1970) first theorized on spending money as a plausible capability indice (costly signal) but concluded, "once the money is spent it does not increase the incentive to follow the policy it was spent on since the money is a 'sunk cost' and thus irrelevant to the calculation of gains and losses that alternative policies entail" (93).
} 
actions can simultaneously sink costs and tie hands. ${ }^{6}$

Despite Slantchev's reconceptualization of military signals, much of the literature to this point has remained constrained by these ideal types, fitting costly signals into one of these two categories. While one could conclude there, that military threats are a combination of tying hands and sunk costs, this combination of ideal categories does not capture a key element of military threats. Military action is public and as such ties hands $;^{7}$ it pays costs up front and as such sinks costs. However, in addition to incurring audience costs and spending money, military signals alter the local balance of power. ${ }^{8}$ Audience costs, which are Fearon's ideal tying hands signal, do not shift the balance of power during a crisis. Military signals, such as military mobilization, the deployment of troops, etc., also increase a state's first strike advantage should war break out or at least ease the difficulties of a second strike response. This is not reflected in either model of ideal types. Lumping audience costs and military maneuvers into one category of "tying hands" obscures a key distinction. Tying hands through audience costs mechanisms refers only to the expected utility of war for the signaler/challenger; tying hands through military signals alter the balance of power through mechanisms such as first-strike advantages in a way that affects the expected utility of war for both sides. It positively affects the signaler's expected utility for war while decreasing the expected utility of war for the receiver of the signal. ${ }^{9}$

As such, military signals 1) sink costs, 2) increase the expected utility of war for the signaler (tying hands), and 3) decrease the probability of victory in a dispute for the receiver of the signal (balance of power shift). With a purely sunk costs signal, the defender gains information about the other side's resolve but only the challenger incurs costs. With a tying hands signal in the strain of audience costs, the challenger pays the costs if he backs down but the defender again pays no costs. However, when a signal shifts the balance in power,

\footnotetext{
${ }^{6}$ See also Letzkian and Sprecher (2007).

7 "Measures such as troop deployments and public threats make crises public events in which domestic audiences observe and assess the performance of the leadership" (Fearon 1994a:577).

${ }^{8}$ For a discussion of the role of the pre-crisis balance of power in bargaining, see Powell (1999).

${ }^{9}$ This of course assumes that the balance of power is a critical component of crisis negotiations.
} 
this is affecting the expected utility of war for both sides, regardless of the other state's response. When the challenger employs a signal that shifts the balance of power in its favor, if shifts the balance of power against the defender. Costless ex ante signals increase the probability of war but the balance-of-power shifts the expected probability of winning said war in favor of the signaler. ${ }^{10}$

To clarify, pure audience costs affect the incentives of the signaler: war may now look more attractive than backing down. However, if the signal alters the balance of power, it makes war look more attractive to the signaler and much less attractive to the state on the receiving end. The first does not affect war-fighting capabilities, the latter does. The first affects the sender's incentives to wage war, the latter affects both sides' incentives to wage war. The other side is now at a strategic disadvantage. Thus, Fearon (1997:78) is right in noting that in a crisis, there is an incentive to tie ones hands "because it rearranges the incentives a person will face in the future, and the knowledge of this can help in bargaining." Ultimately, while the objective of a hand-tying signal it to manipulate the sender's future payoffs, the signal that entails a shift in the balance of power also manipulates the receiver's future payoffs. This complicates a state's decision-making calculus. For the rest of this paper, when I refer to "tying hands" signals I am referring to the pure type in which states do not shift the balance of power.

\section{The Trade-Off}

A state that needs to signal its resolve struggles with a difficult trade-off in costly signaling. A costly signal of resolve may communicate private information; but if it has any element of tying hands, the signal locks the state into a bargaining position that also increases the probability of war. ${ }^{11}$ A state must balance between gaining leverage in bargaining and

\footnotetext{
${ }^{10}$ This increased probability of winning the war may also give the challenger an incentive to wage war as well. Either way, the balance-of-power change has shifted the winning of the war in the challenger's favor.

${ }^{11}$ This is the classic deterrence model versus the spiral model. Deterrence model theorists argue for a strong stand to show the other side its willingness to wage war. Spiral theorists argue that tough stands can be dangerous against a pure security seeking state, dragging both states into unwanted war. The deterrence
} 
increasing the probability of conflict. In addition to this, states not only choose whether to send a costly signal, they must also choose the type, intensity, and publicity of their signal. Strategic actors must deal with the trade-offs: should a state signal all or nothing to clearly demonstrate his willingness to wage war or should it hedge its bets with a less costly or conspicuous message?

The paper assumes that states strategically choose first whether or not to take a costly military move to signal resolve, and second from their toolbox of potential signals the most appropriate type and level of force to send that signal. Based on a mixture of sunk costs and tying hands, different predictions arise concerning the other state's response. Instead of analyzing the selection process into a crisis, for the purposes of this project the state has already chosen to enter a crisis by making a threat. It has already chosen to employ public rather than private diplomacy to resolve its dispute (Trager 2010). Its reputation of behavior in crises is already established. The challenger has an interest in gaining concessions and must now determine how to communicate its resolve, bluff, or create resolve, preferably short of war.

Private information is a double-edged sword for the initiator in a crisis. If private information was known, it could easily demonstrate its willingness to wage war over an issue. On the other hand, because there is private information, a state can attempt to manipulate signals in a way that convinces the other side that it has resolve even when it does not. The key is now to choose the best method. In this study's analysis, a state can choose purely verbal threats, but it can also choose to enhance those threats with a military demonstration. However, even after deciding to escalate in this manner, the state must make a decision for the level and type of force it wants to employ. Should a state prepare its troops for war? Should it display its air power? Should it increase the intensity of the signal and use all of the available options? Slantchev (2005:539) predicts "that crises that are peacefully resolved may involve higher military allocation than those that end in war." Signaling all or nothing model assumes the "other" has aggressive intentions; the spiral model assumes the "other" has status quo intentions. See Jervis (1976, chapter 3) for a discussion of the opposed predictions of these models. 
may be the most effective way of gaining concessions. Of the options available, a strategic actor will want to make a trade-off between maximizing the probability of prevailing in a crisis and minimizing the probability of war. Not all credible threats will ensure peace.

This paper necessarily dips into the literature on reputations for resolve. There is indeed great debate on whether a state can develop a reputation based on past actions. Decisionmakers evaluate other states' credibility based on their history for keeping or breaking their commitments. On the other hand, Press (2005) advocates in his "Current Calculus" theory that past actions are only useful in that they demonstrate a state's interests and power. Rather than a state caring about its adversary's history of keeping commitments, it seeks insight into the interests and power of the other state in the current crisis. In this way, his theory argues that a state should seek to clearly emphasize its power and valuation of the issue. For theories of costly signaling, however, a military signal is about a willingness to fight, not valuation of the issue itself (Slantchev 2005:541). Indeed, states will calculate their interests and power before issuing a threat. However, after chooses to issue that threat, that state must decide how best to communicate the seriousness of that threat. "...in models of isolated disputes [reputations] are merely assumed" (Sartori 2005:44; see also Fearon 1992).

While I do not incorporate private diplomacy into my theory and empirical testing, it is not because I believe that diplomacy is worthless. Indeed, the literature has made clear that states can successfully negotiate privately to avert war and gain concessions. ${ }^{12}$ This paper's question starts from a different premise: Considering that a nation has already chosen to go public, what options does it choose to employ? It can choose a purely ex ante costless stand, as the audience costs literature predict. However, he can also employ public military measures of varying degrees and type. It is in these situations that states also have the greatest incentives to misrepresent their information (Fearon 1995) so must seek to establish the credibility of their threat (Jervis 1970).

\footnotetext{
${ }^{12}$ Sartori (2005), Trager (2010), Kurizaki (2007), Guisinger and Smith (2002), Jervis (1970), Kydd (2003), Ramsay (2004), Schelling (1966) and (1980).
} 


\section{Testable Hypotheses}

The above discussion poses three clearly testable hypotheses concerning the effectiveness of a costly signal in the context of coercive threats. The literature is united around the idea that a costly military signal should increase the effectiveness of a coercive threat, despite the increased risk of war. Since all military signals are tying hands signals, military signals should entail a successful category of coercion. This hypothesis primarily distinguishes between the effectiveness of purely verbal threats and those coupled with military force.

Hypothesis 1: Military Signal. A costly signal of force, whether tying hands or sunk costs or some combination of the two, will increase the effectiveness of a coercive threat.

In addition, a tying hands signals that entails a shift in the balance of power should, based on theories that predict favorable bargaining outcomes for the stronger state, increase the effectiveness of a coercive threat (ceteris paribus). This may also have something to do with the revelation of capabilities in the crisis, allowing the other side to update his estimation of the other side's power. It may entail the an added first-strike advantage. "To the extent that relative capabilities and interests are observable before a crisis begins, rational challengers should take these into account" (Fearon 1994a:238). A military signal should alter the other side's estimation of the signaler's capabilities and resolve or actually alter the short-term balance of power. Those signals that entail both a revelation of and a shift in the balance of power should increase the effectiveness of the threat.

Hypothesis 2: BOP. Costly signals that alter the balance of power in favor of the challenger will be associated with higher level of threat success.

Fearon (1997:71) predicts that we should see tying hands signals more frequently and that a state should do better with a strictly tying-hands signal. He notes, "I believe that it is a defensible empirical intuition that international crises are characterized more by public contests to generate audience costs that by spending contests in which states sink costs to signal resolve." $\mathrm{He}^{13}$ doubts that sunk costs will not be effective at achieving coercive success.

\footnotetext{
${ }^{13}$ See also Jervis (1970)
} 
However, there is reason to believe that tying hands signals that also sink costs should be more effective than a purely tying hands signal. The combined increase in costs should reflect a more resolved actor.

Hypothesis 3: Sunk Costs. Costly signals that entail higher levels of sunk costs combined with tying hands effects will increase the effectiveness of coercive threats.

In order to test hypotheses 2 and 3, I develop empirical predictions concerning what combinations that costly military signals entail. The following section theorizes the differences among land, air, and naval signals, based on their combination of tying hands, sunk costs, and balance of power elements.

\section{Land}

Land signals include public military mobilization and troop deployment and may include marine or naval infantry movement and land-based air mobilization. Military mobilization refers to the preparation but not the movement of troops. It is a high sunk costs signal with a medium shift in the balance of power. Troop deployment actually moves the troops into another area, thereby strongly shifting the balance of power in the signaler's favor in addition to sinking costs. Both have elements of tying hands because they are highly public and committal. According to Hypotheses 2 and 3, troop deployment and mobilization should be associated with high levels of compellent threat success due to this unique combination of types of costly signals. ${ }^{14}$

\section{Naval}

Amphibious forces include naval forces of all kinds; the use of gunboat diplomacy usually entails moving the naval units closer to a potential theater of operations. Blechman and Kaplan (1978:41) note that this signal is an appealing move for states that seek some flexibility, because naval forces are easier to move about than land forces. They are less disruptive,

\footnotetext{
${ }^{14}$ Future research will distinguish between mobilization and deployment. This iteration of the project only codes Land signals.
} 
subtler, and have less of a hand tying effect. They are primarily sunk costs signals that shift the local balance of power only slightly. Aircraft carriers are a subset of this category. Based on Hypothesis 2 and 3, naval forces will be associated with the second highest level of compellent threat success due to this unique combination of signal types: medium on the tying hands continuum, low on the sunk costs, and low on the balance of power. Signals that allow leaders more flexibility in bargaining should be associated with less success (see Fearon 1997).

\section{Air Power}

"Buzzing an airplane in the Berlin corridor does no harm unless the planes collide; they probably will not collide but they may and if they do the result is sudden dramatic, irreversible, and grave enough to make even a small probability a serious one" (Schelling 1996:91). Air power, specifically bomber over-flights, is a tying hands signal with very public efforts at manipulation of risk. Pape (1996) theorizes four uses of air power but only one - the manipulation of risk - applies to crisis bargaining interested in the show rather than the application of force. This signal is nearly costless up front (low on sunk costs), but risks the initiation of war or accident that leads to war, categorizing them as high on the tying hands continuum. Due to their flexibility, they rarely entail a huge shift in the balance of power, unless they are employed to deliver land troops to the arena of operations.

Hypothesis 2 (BOP) predicts that air power is the least effective military signal because it does not shift the balance of power. Hypothesis 3 (sunk costs) makes similar predictions about naval and air power. Naval is medium on the sunk costs continuum but low on the tying hands continuum, but air is low on the sunk costs and high on the tying hands continuum. Because of the countervailing predictions, Hypothesis 3 predicts naval and air power to have similar effects. This distinction differentiates Hypothesis 2 from Hypothesis 3. Predictions concerning the balance of power would expect the following order of effectiveness: Land $\rightarrow$ Naval $\rightarrow$ Air. Hypothesis 3 predicts Land $\rightarrow$ Naval and/or Air. Should Fearon 
be right concerning his predictions of tying hands, we would expect Hypothesis 1 to be correct - costly signals increase the effectiveness of a coercive threat versus not costly signal - but variations in sunk costs and power balances should not matter. Land, air, and naval demonstrations should be equally effective for Fearon's intuition to hold.

\section{Summary of Predictions}

Table 1: Types of Military Signals

\begin{tabular}{lccc}
\hline Demonstration of Force & Sunk Costs & Tying Hands & Balance of Power \\
\hline Military Mobilization & High & Medium & Medium \\
Troop Deployment & High & High & High \\
Naval & Medium & Low & Medium \\
Air & Low & High & Low \\
\hline
\end{tabular}

\section{Research Design and Data}

While in future the goal is to expand this research to crisis signaling more generally, this paper tests the effects of military demonstrations on the success of compellent threats. This paper employs the Militarized Compellent Threats (MCT) dataset, which contains information on 210 interstate compellent threats (among 242 dyads) between 1918 and 2001. Each case in the data set contains a compellent threat, defined as a coercive demand to change the status quo that is backed by the threat of military force. Mostly the threats to use force are communicated verbally, but they may also be communicated implicitly (but still conspicuously) through military signals.

In this dataset, the challenger issues a threat and target must in turn choose to resist or 
concede. ${ }^{15}$ Thus, the challenger employs compellence, a category of coercion in which the challenger makes an effort to alter the status quo, seeking to change another actor's behavior. This contrasts with deterrence in which the challenger seeks to make another actor refrain from certain behavior. Schelling argues that compellence is easier to demonstrate but more difficult to achieve than deterrence. With compellence, it is clear when a state has acceded to concessions, while in deterrence it is more difficult to assess whether the state chose to refrain from a particular action due to the threat or any pre-existing intention. Using the MCT dataset is a good first cut at testing the empirical predictions of these costly signals, because the category of "success" is clearly defined. We can clearly determine when a threat coupled will military force was issued and accomplished its objectives.

\section{Dependent Variable}

The dependent variable is TARGET COMPLIANCE. The dataset categorizes the target's response to the challenger's demand as 1) non-compliance, cases which entail no target concessions to challenger demands, 2) partial compliance, cases in which the target acquiesces to some but not all of of the challenger's demands, and 3) full compliance, cases in which the target complies fully (or nearly so) to the challenger's demands. The variable TARGET COMPLIANCE is coded 1 if the target voluntarily complies with all of the demands of the challenger (category 3) and the challenger does not employ military force to achieve its demands. It is coded 0 otherwise (categories 1 and 2).

Further specifications of the dependent variable are included in the first stages of the statistical analysis. The variable PARTIAL COMPLIANCE in Model 3 is the dependent variable recoded using a more lenient standard for target compliance, classifying threats as successful if the target complied with any - as opposed to all - of the challengers demands.

Second, for both TARGET COMPLIANCE and PARTIAL COMPLIANCE, I defined a

\footnotetext{
${ }^{15}$ This is different from Fearon (1997) in which the challenger issues a request, and the defender must choose whether or not to respond with a costly signal. Trager (2010) argues that the target has more than two options.
} 
successful threat as one that achieved compliance with no military force. However, compellence more generally can entail the application of force. This study primarily analyzes the success of compellent threats short of violence but the variable FORCE in Model 4 reclassifies compellent threats as successful if the target complied with any of the challengers demands even if the challenger used limited military force, as long as the target suffered fewer than 100 fatalities. This variable does not test the theory of costly signals as closely, because the actual application of force detracts from the clarity of the signal. It is difficult to assess whether the signal of or the application of force results in compliance. Inclusion of this variable is primarily a robustness check.

\section{Independent Variables}

During the first cut of the empirics, the independent variable of interest is SIGNAL, a dichotomous variable that takes a value of 1 if the challenger sent a military signal (a visible military demonstration or mobilization or other show of force) in a crisis, and 0 otherwise. This variable tests Hypothesis 1, whether a costly military signal of any sort increases the effectiveness of compellent threats.

In addition to this, the theory developed in this paper needs to disaggregate costly military signals to differentiate land, air, and naval demonstrations from each other. As discussed in the previous section, land, air, and naval demonstrations range from having tying hands effects which do not affect a war outcome and effects that can potentially affect a war outcome (BOP), and all entail some level of sunk costs. Based on Hypothesis 2 and the summary of predictions in Table 1, land signals should be more effective at achieving compellent threat success than naval forces, and naval forces should be more effective than air power. Hypothesis 3 predicts that signals that entail high levels of tying hands in addition to sunk costs should be most effective. Land signals - which are high on the tying hands type and the sunk costs type - will be more effective then either naval or air signals. The distinction between naval and air signals is indeterminate, because naval power has low 
tying hands abilities and medium levels of sunk costs, while air has high levels of tying hands abilities and low levels of sunk costs.

Lastly, to get at the idea that states should signal "all or nothing" in order to achieve their goals, I further disaggregate this to include combination cases. A combination of land with naval or air power should be associated with the highest level of compellent threat success according to Hypotheses 2 and 3, because the increased level of sunk costs and alterations in the balance of power should increase the effectiveness of the threat.

The current dataset includes a variable that disaggregates SIGNAL for the years 19181956 into an indicator variable into four categories, LAND, NAVAL OR AIR, and COMBINATION. The base category is the absence of a costly signal. LAND includes both military mobilizations and deployments. NAVAL OR AIR includes naval and/or air power as a costly signal. COMBINATION entails military mobilization employed in combination with either air or naval power.

Future iterations of this project will code post-1956 data, allowing me to divide the variable NAVAL OR AIR. As it is, there is not enough data on the use of air power prior to 1956 to include it alone in the dataset. Due to these limitations, I cannot distinguish between hypotheses 2 and 3, both of which predict that land power will more effectively signal resolve than either land or naval power but make different predictions concerning the effectiveness of land and naval power compared to one another.

\section{Control Variables}

Balance of Power. Because my interpretation of the differences in tying hands signals relies heavily on shifts in the balance of power during a crisis, the analysis includes a variable that captures the ex ante balance of capabilities, CAPABILITY RATIO, a continuous variable ranging from 0 to 1 . The power balance leading into the crisis will affect the success of a signal. If the states are relatively equal in power, a more costly signal will be necessary to not only demonstrate resolve but shift the balance of power in the challenger's favor. While 
theories predict that a favorable balance of power will result in favorable crisis outcomes, theories of reputation argue that there are reasons for a weaker state to resist threats made by a more powerful state to develop a reputation for toughness (Sechser 2010). The Correlate's of War Composite Index of National Capability (CINC) ratio measures the relative balance of power between the crisis dyad. It measures the proportion of material capabilities controlled by the challenger in each dyad (Singer, Bremer, and Stuckey 1972). ${ }^{16}$

Stakes and Interests. The MCT dataset classifies each compellent threat according to the issue at stake. Much of the research on signaling emphasizes the importance of the issues at stake (George and Simons 1994).

- TERRITORY: If the challenger is demanding territorial concessions or the removal of military from the disputed area, this observation is coded as a territorial possession.

- REPARATIONS: This category entails demands for compensation of perceived or actual injustices.

- LEADERSHIP: The challenger demands the removal of an individual within the target's government.

- POLICY: The challenger demands changes in the target's national policy. This does not entail territorial concessions.

- OTHER: This base category includes all other demands that do not fall naturally into one of the four above categories.

Geographic Proximity. Land demonstrations may be highly correlated with the contiguity relationship of a dyad. If two states are contiguous, land demonstrations will be easier and potentially more effective at gaining concessions. On the other hand, contiguous states are at a higher risk of entering a crisis together in the first place, so target states may be more likely to resist demands. States may also have to employ higher levels of force

\footnotetext{
${ }^{16}$ I run additional regressions with 1) military spending, 2) nuclear challenger and nuclear target, 3) great power challenger and great power target. The model is robust to all specifications of this variable.
} 
to demonstrate resolve. The Correlates of War (COW) Direct Contiguity dataset includes data on the contiguity relationship for dyads separated by a land or river border. This CONTIGUITY variable is equal to 1 if the states in the crisis dyad are only separated by a land or river border and 0 otherwise.

Dispute history. States with a high frequency of conflict are more prone to conflict in the future. This also suggests unresolved issues within the dyad that will repeat themselves into the future. The variable DISPUTE HISTORY measures the total number of militarized interstate disputes that the challenger and target have experienced during the previous fifteen years (Maoz 2005).

Alliances. A threat issued by multiple challengers may more likely to succeed. The COALITION variable accounts for whether the threat is jointly issued.

Regime Type. The literature on audience costs and democratic credibility argues that democracies can incur higher levels of audience costs or have institutional constraints that increase the credibility of their threats (Gelpi and Grieco 2002, Schultz 2001; but see Sechser and Downes 2012). This analysis includes two variables to account for the effects of regime type, DEMOCRATIC CHALLENGER and DEMOCRATIC TARGET. I include measures of democracy from the Polity IV project (Marshall et al. 2013). Each challenger and target is coded as a democracy if the its Polity IV score is +6 or above.

\section{Empirical Analysis}

Due to the dichotomous nature of the dependent variable, I employ a standard logit model to estimate the success of compellent threats. I cluster by dyad to overcome any potentially inflated standard errors due to repeated dyads in the dataset.

As a first cut, I lump all military demonstrations into one variable: SIGNAL, which indicates whether the challenger employed a costly military signal when making its demand. This variable is significant to all specifications of the dependent variable, but Table 1 reports 
the marginal changes in probability for the core model with Full compliance as the dependent variable. Compared with the coefficients, the marginal changes in probability are more intuitive and useful to understand the effect of costly signals on compellent threat success. Compared with the base model of employing no costly signal, a costly signal of resolve increases the probability of threat success by 0.367 . This result is both statistically (at the 0.001 level) and substantively significant, indicating a $36.7 \%$ increase in the probability of threat success. Costly signals are effective, holding all else constant.

In Models 2-4, I report the key empirics, after disaggregating the dependent variable in the the categories of land, naval and/or air, and combination. Model 2 is the most important, as it is a "hard test" of whether military signals can gain full concessions from the target. Compared with the base model of employing no costly signal, a land signal increases the probability of threat success by 0.413 . This result is both statistically (at the 0.001 level) and substantively significant, indicating a $41.3 \%$ increase in the probability of threat success. Compared with the base model of employing no costly signal, an air or naval signal increases the probability of threat success by 0.380 . This result is both statistically (at the 0.001 level) and substantively significant, indicating a $38.0 \%$ increase in the probability of threat success. Compared with the base model of employing no costly signal, employing combination of land signals with naval or air force increases the probability of threat success by 0.512 . This result is both statistically (at the 0.001 level) and substantively significant, indicating a $51.2 \%$ increase in the probability of threat success. 


\begin{tabular}{|c|c|c|c|c|}
\hline & $(1)$ & $\begin{array}{c}(2) \\
\text { Full Compliance }\end{array}$ & $\begin{array}{c}(3) \\
\text { Any Compliance }\end{array}$ & $\begin{array}{c}(4) \\
\text { Compliance with Force }\end{array}$ \\
\hline SIGNAL & $\begin{array}{c}0.367^{* * *} \\
(0.071)\end{array}$ & & & \\
\hline LAND & & $\begin{array}{c}0.413^{* * *} \\
(0.071)\end{array}$ & $\begin{array}{c}0.372^{* * *} \\
(0.085)\end{array}$ & $\begin{array}{c}0.403^{* * *} \\
(0.091)\end{array}$ \\
\hline NAVAL AND/OR AIR & & $\begin{array}{c}0.380^{* * *} \\
(0.097)\end{array}$ & $\begin{array}{c}0.405^{* * *} \\
(0.107)\end{array}$ & $\begin{array}{c}0.536^{* * *} \\
(0.115)\end{array}$ \\
\hline COMBINATION & & $\begin{array}{c}0.512^{* * *} \\
(0.156)\end{array}$ & $\begin{array}{c}0.608^{* * *} \\
(0.160)\end{array}$ & $\begin{array}{c}0.667^{* * *} \\
(0.132)\end{array}$ \\
\hline CONTIGUITY & $\begin{array}{c}0.048 \\
(0.059)\end{array}$ & $\begin{array}{l}0.122^{\dagger} \\
(0.084)\end{array}$ & $\begin{array}{c}0.145 \\
(0.082)\end{array}$ & $\begin{array}{c}0.156^{* *} \\
(0.086)\end{array}$ \\
\hline CAPABILITY RATIO & $\begin{array}{l}-0.192^{*} \\
(0.094)\end{array}$ & $\begin{array}{l}-0.093 \\
(0.136)\end{array}$ & $\begin{array}{l}-0.082 \\
(0.131)\end{array}$ & $\begin{array}{r}-0.294^{*} \\
(0.148)\end{array}$ \\
\hline TERRITORY & $\begin{array}{l}-0.076 \\
(0.058)\end{array}$ & $\begin{array}{l}-0.056 \\
(0.080)\end{array}$ & $\begin{array}{l}-0.102 \\
(0.075)\end{array}$ & $\begin{array}{l}-0.097 \\
(0.071)\end{array}$ \\
\hline REPARATIONS & $\begin{array}{l}-0.089 \\
(0.098)\end{array}$ & $\begin{array}{l}-0.081 \\
(0.105)\end{array}$ & $\begin{array}{c}0.021 \\
(0.100)\end{array}$ & $\begin{array}{c}0.013 \\
(0.095)\end{array}$ \\
\hline LEADERSHIP & $\begin{array}{c}0.301^{* * *} \\
(0.084)\end{array}$ & $\begin{array}{l}0.280^{*} \\
(0.112)\end{array}$ & $\begin{array}{c}0.288^{* *} \\
(0.109)\end{array}$ & $\begin{array}{r}0.370^{* *} \\
(0.118)\end{array}$ \\
\hline POLICY & $\begin{array}{l}-0.002 \\
(0.054)\end{array}$ & $\begin{array}{l}-0.053 \\
(0.067)\end{array}$ & $\begin{array}{l}-0.098 \\
(0.068)\end{array}$ & $\begin{array}{l}-0.108 \\
(0.072)\end{array}$ \\
\hline DISPUTE HISTORY & $\begin{array}{r}-0.013^{\dagger} \\
(0.007)\end{array}$ & $\begin{array}{l}-0.012 \\
(0.012)\end{array}$ & $\begin{array}{l}-0.005 \\
(0.012)\end{array}$ & $\begin{array}{l}-0.015 \\
(0.012)\end{array}$ \\
\hline COALITION & $\begin{array}{c}-0.211^{* * *} \\
(0.063)\end{array}$ & $\begin{array}{c}-0.372^{* * *} \\
(0.087)\end{array}$ & $\begin{array}{c}-0.360^{* * *} \\
(0.098)\end{array}$ & $\begin{array}{l}-0.250^{*} \\
(0.109)\end{array}$ \\
\hline DEMOCRATIC CHALLENGER & $\begin{array}{c}0.003 \\
(0.065)\end{array}$ & $\begin{array}{l}-0.097 \\
(0.094)\end{array}$ & $\begin{array}{l}-0.001 \\
(0.103)\end{array}$ & $\begin{array}{l}-0.041 \\
(0.109)\end{array}$ \\
\hline DEMOCRATIC TARGET & $\begin{array}{l}0.142^{*} \\
(0.063)\end{array}$ & $\begin{array}{c}0.082 \\
(0.080)\end{array}$ & $\begin{array}{l}0.151^{*} \\
(0.075)\end{array}$ & $\begin{array}{l}0.126^{\dagger} \\
(0.073)\end{array}$ \\
\hline$N$ & 236 & 128 & 128 & 128 \\
\hline
\end{tabular}

Robust standard errors in parentheses ${ }^{* * *} \mathrm{p}<0.001,{ }^{* *} \mathrm{p}<0.01,{ }^{*} \mathrm{p}<0.05, \dagger \mathrm{p}<0.1$

Table 2: Marginal changes in probability for compellent threat success 
While military demonstrations clearly have a positive effect on the probability of target compliance, the results do not support either Hypothesis 2 or Hypothesis 3. Figure 1 compares the effectiveness among the categories costly military signals. Land signals and land combined with air or naval force appear to have the predicted stronger effect on target compliance than land and/or naval signals, but these results are not statistically significant. Fearon's intuition - that it is the tying hands aspects of military signals rather than the added elements of sunk costs, etc. - holds up under these findings. He predicts that sunk costs will have a miniscule additional effect on the effectiveness of signals. ${ }^{17}$

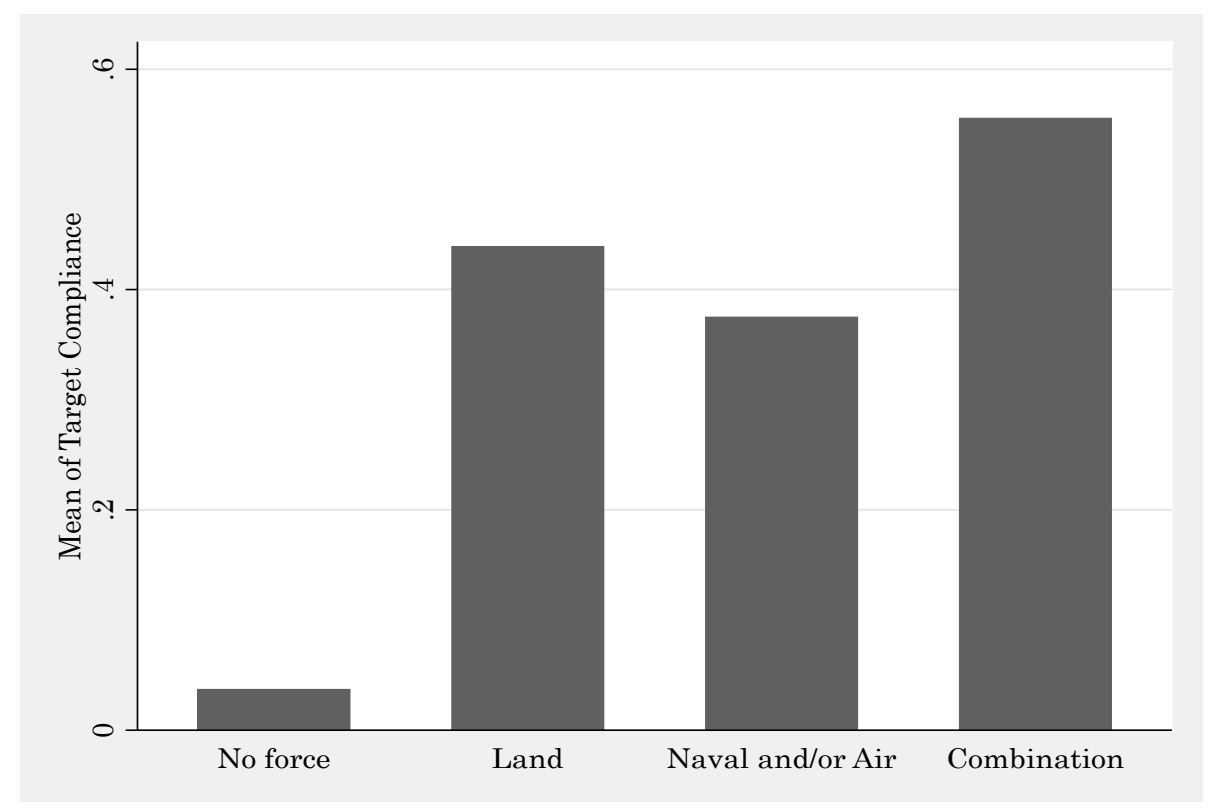

Figure 1: A Comparison of Costly Signals

To account for potential interactions among the variables, I discuss three more models. I presume that land force should be highly correlated with contiguity $(\rho=0.2597)$. Model 5 includes an interaction for that term. Land continues to be statistically significant to this variation in the model, whether or not the two states are contiguous. The difference between land signals between contiguous states and land signals between non-contiguous states is

\footnotetext{
${ }^{17}$ Returning to the case study at the beginning of this paper, President Obama's failure to follow through on his first "red line" threat may have degraded his ability to further tie his hands. This would explain why Pres. Obama's second attempt to coerce the Syrian regime was a failure: he was unable to employ the most effective signal, the tying hands signal.
} 
statistically insignificant $\left(\chi^{2}=1.27\right.$, prob $\left.>\chi^{2}=0.2607\right)$. Compared with the base model of employing no costly signal, a land signal between two non-contiguous states increases the probability of threat success by 0.366 . This result is both statistically (at the 0.001 level) and substantively significant, indicating a $36.6 \%$ increase in the probability of threat success. Compared with the base model of employing no costly signal, a land signal between two contiguous states increases the probability of threat success by 0.503 . This result is both statistically (at the 0.001 level) and substantively significant, indicating a $50.3 \%$ increase in the probability of threat success. Table 3 reports the effects of the key variables of interest and Figure 2 demonstrates this graphically. Land signals do appear to have a stronger effect (substantively) when the two states are contiguous that when they are non-contiguous. Still, these differences are not statistically significant.

\begin{tabular}{lc}
\hline & $(5)$ \\
& Contiguity Interaction \\
\hline LAND, NON-CONTIGUOUS & $0.366^{* * *}$ \\
& $(0.085)$ \\
& $0.503^{* * *}$ \\
LAND, CONTIGUOUS & $(0.103)$ \\
& $0.372^{* * *}$ \\
NAVAL AND/OR AIR & $(0.109)$ \\
& $0.505^{* *}$ \\
COMBINATION & $(0.165)$ \\
& \\
$N$ & 128 \\
\hline Robust standard errors in parentheses & \\
$* * * \mathrm{p}<0.001, * * \mathrm{p}<0.01, * \mathrm{p}<0.05, \dagger \mathrm{p}<0.1$ &
\end{tabular}

Table 3: Marginal changes in probability with contiguity interaction 


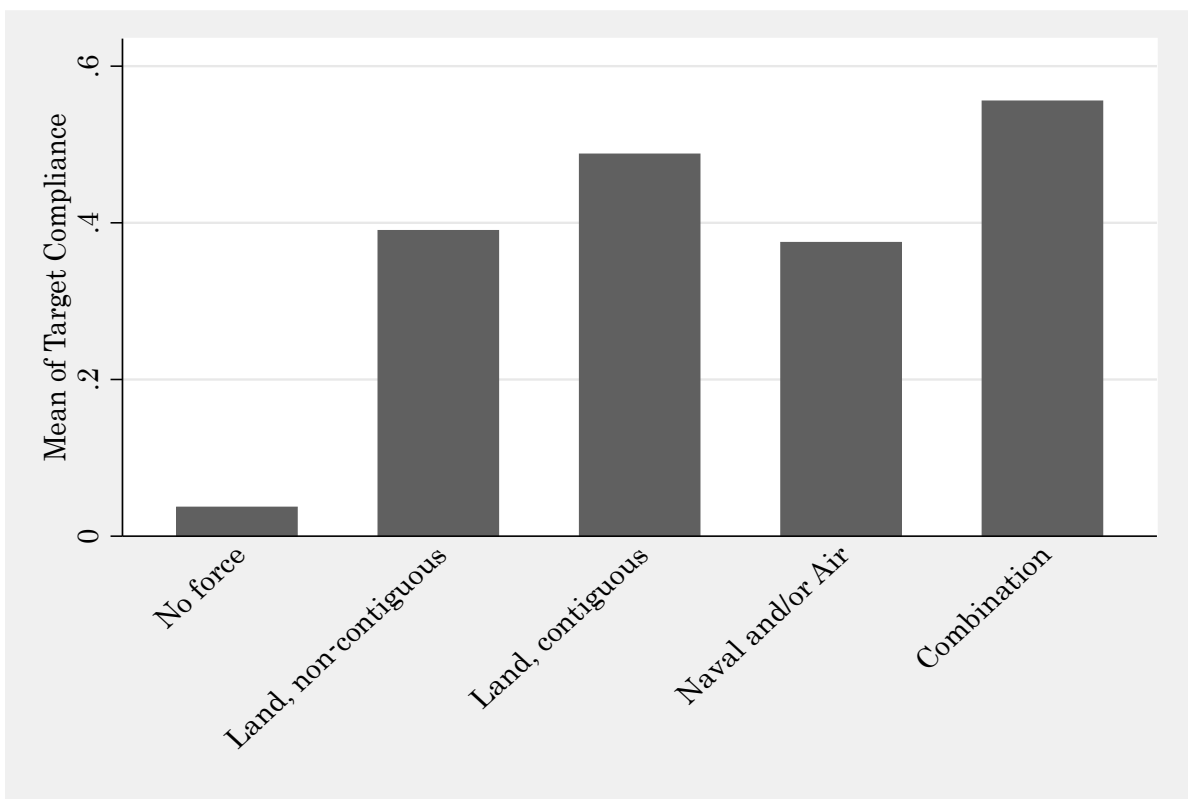

Figure 2: A Comparison of Costly Signals

I also interact LAND, NAVAL OR AIR, and COMBINATION with CAPABILITY RATIO (a continuous variable ranging from 0 to 1 ) to account for any potential interactions between overall capability differences and the choice of military signal. I do not report the coefficients or the marginal changes in probability in this case as interactions with continuous variables (CAPABILITY RATIO) are not naturally interpretable (and the coefficients even less so). Rather, I graphically interpret this variable as it interacts with each tool of force. Figure 3 reports the effect of land signals at 0.1 intervals of capability ratios. There appears to be no significant difference at any intervals. The same results hold for combination effects in Figure 5. However, Figure 4 indicates that naval and/or air signals are much less effective when the challenger's relative military capabilities increases significantly. This is a surprising and somewhat counterintuitive finding, although in line with predictions by those in reputations literature. Sechser (2010) argues that weaker states have an incentive to resist more powerful state's demands in an effort to build a reputation for toughness to deter future concessions. 


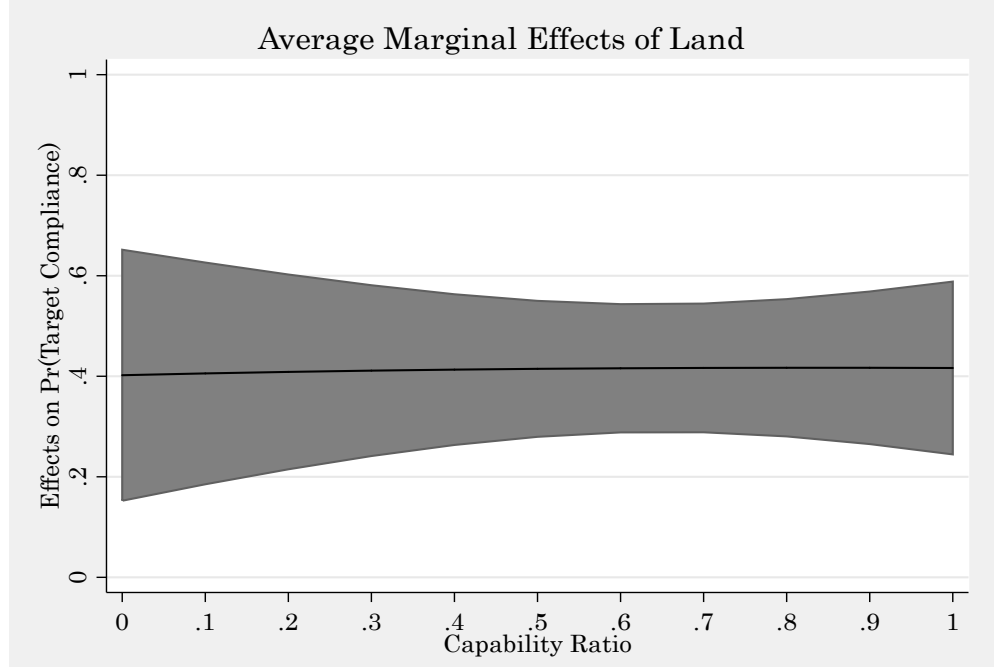

Figure 3: Capability Ratio interacted with Land

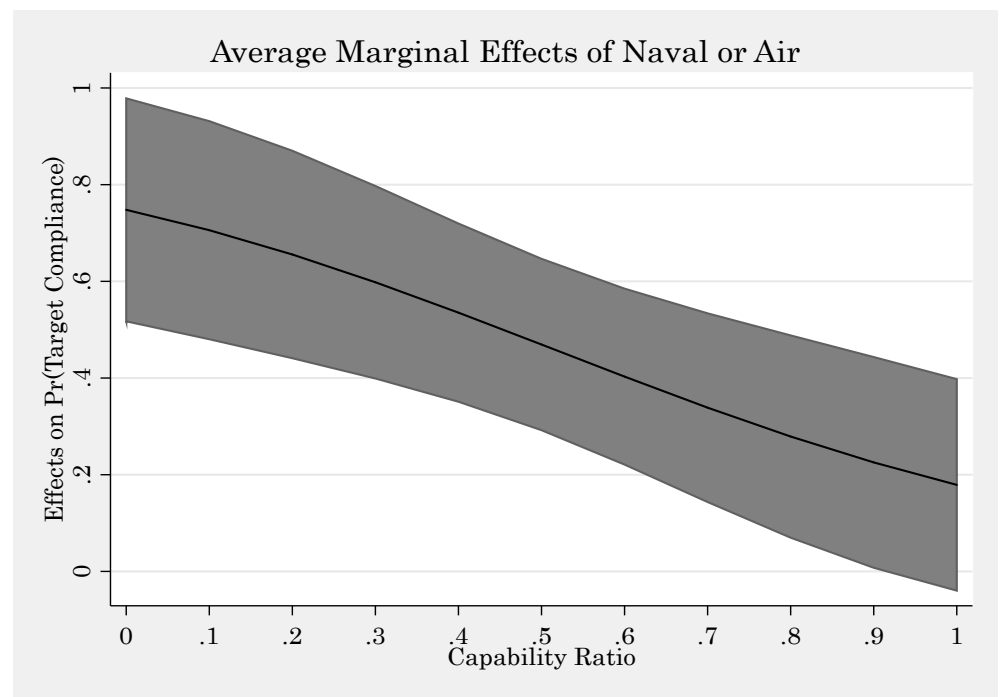

Figure 4: Capability Ratio interacted with Naval or Air 


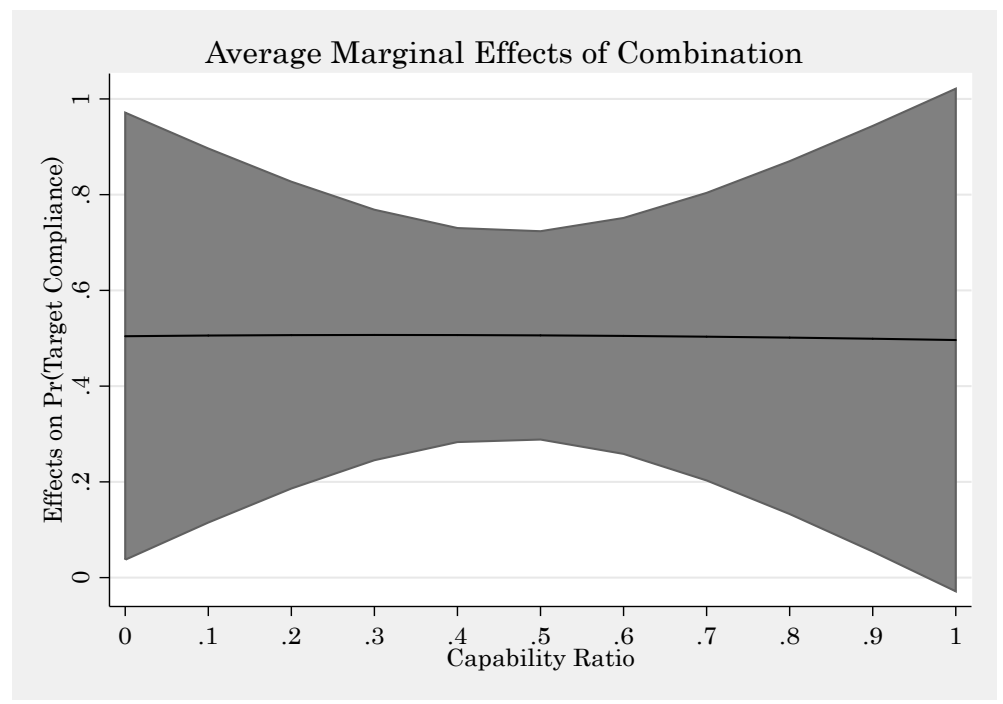

Figure 5: Capability Ratio interacted with Combination

To summarize, the models run here find support for Hypothesis 1, but no (statistically significant) support for Hypotheses 2 and 3. See the Conclusions and Implications section for further discussion and potential paths of future research based on this findings.

\section{Selection Effects}

This section of the paper analyzes this theory of crisis bargaining through the lens of the counterfactual model in an effort to delineate any potential sources of bias in this observational study. The primary difference between an experiment and an observational study such as this is the assignment mechanism. In an observational study such as this one, nature determines unit assignment to treatment and control, and the researcher cannot assign states to treatment in control or know the actual treatment selection mechanism.

The fundamental problem of causal inference (FPCI) is that we cannot observe the same unit in both treatment and control; this inhibits our ability to make causal inferences. To establish internal validity and to alleviate the fundamental problem of causal inference, I would ideally develop a randomized controlled experiment to test these hypotheses. My ideal dataset would consist of randomly assigned crises of the world with three treatment groups in which the challenger employed demonstrations of naval, land, or air force, and one 
control group, with the challenger choosing to employ no military signal. The differences in target compliance among the groups will demonstrate the average causal effect (ACE) of military signals. I could infer this causal relationship with a high level of confidence, because random assignment allows me to isolate and test only the effect of naval, land, and air power on target compliance without potential confounding influences.

\begin{tabular}{c|c|c|c} 
Control Group & Treatment Group 1 & Treatment Group 2 & Treatment Group 3 \\
\hline No costly signal & Land demonstration & Naval demonstration & Air demonstration
\end{tabular}

Table 4: Ideal Experiment

This ideal experiment does not exist for this study, because the scholar/investigator cannot control the assignment of treatment (tool of force) to subjects. We do not know the treatment selection mechanism. For every case that a challenger chooses to employ force, we cannot observe the counterfactual of what would happen if that challenger did not employ force during the crisis or chose a different tool of force. The empirics indicate that employing a costly signal of resolve increases threat effectiveness (i.e. increases the probability of target compliance). However, the question is not, how effective is using force in the case compared to the other cases? The real question is, would this threat have had the same probability of success had the state chosen a different option to demonstrate resolve? Should the theories discussed here be right, if states did not employ these weapons during a crisis, their threat would have been less likely to achieve target compliance. Without being able to observe this counterfactual, we cannot be certain that had the state chosen another means to demonstrate resolve that it would have been more or less effective.

The states in this study self select themselves into treatment and control. Without knowledge of the selection mechanism, employing the nonuse of force in some crises as the base category may not adequately test the theory. If leaders are choosing strategically, they are choosing the strategy that has the highest probability of success, therefore biasing 
our treatment effect estimate of military signals as associated with higher levels of threat success. This is nonrandom sample selection, or selection bias. By selecting its treatment non-randomly, this makes it difficult for a researcher to make comparisons to other nonsimilar cases (which is what this study does). ${ }^{18}$ Controlling for potential confounders to make the cases more similar helps, but further analysis of the selection mechanism will better address this problem. I discuss this further in the following Conclusions and Implications section.

\section{Conclusions and Implications}

This project asks the following question: Given that a state has already selected into a crisis, what military signals at its command will be most effective in gaining concessions from a target? It found, in an analysis of militarized compellent threats, that costly signals of resolve increase the probability of target compliance (and therefore bargaining success). It also found that while these tying hands signals ${ }^{19}$ have a positive effect, different levels of sunk costs and additional shifts in the balance of power entailed by different military signals do not alter the effectiveness of a threat. That is, naval, land, and air signals - which all tie hands to varying degrees and entail different levels of sunk costs - do not have statistically different effects on target compliance. This finding contributes an interesting confirmation of Fearon's intuition.

Future research should explore two puzzles this analysis has raised. Although this paper finds no confirmatory results concerning the hypotheses on sunk costs and military shifts in the balance of power, future research should explore why it is that variations in land, naval, and air power do not appear have varying effects on coercion. If this is the case, it should not

\footnotetext{
${ }^{18}$ Note also another potential source of bias that this study does not address. "If crises are characterized by private information and costly signaling, then states will select themselves into or out of crises according to these prior beliefs, and this fact will have implications for subsequent inferences and choices" (Fearon 1994a:245).

19 "The notion that troop movements and public demands or threats 'engage the national honor' - thus creating audience costs that leaders would pay if they backed down continues strongly through the nineteen and twentieth centuries" (Fearon 1994a:581).
} 
matter what military signal a state chooses; rather any demonstration of force will alleviate the problem of private information. This has important implications for policy as well. As long as a state takes a firm stand in conjunction with a costly military signal, it will increase the probability of succeeding in a crisis.

Second, why do states employ the tools of force that they do? The FPCI hinders our ability to make perfect causal claims, but does not prevent our ability to make limited causal inferences. This project is a first cut at understanding the relative success of costly signals in crises. Future research should seek to understand the selection process better by assessing why leaders choose the costly signals that they do. I assume that states choose strategically, but leaders may employ certain types and levels of force for domestic, bureaucratic, budgetary, and other reasons. Understanding the calculus will give us clearer predictions about which types of military signals will be most effective. We should also take a step back and look at more than just the decision-making calculus during a crisis. Before choosing to make explicit demands, states have the options of 1) doing nothing, 2) issuing a fait accompli, 3) employing private diplomacy, 4) initiating major war, and a number of other choices.

Concerning the empirics, this analysis is mostly a plausibility test of the effectiveness of signals, only testing it on cases from 1918-1956. Future iterations of this project will expand the data on military signals through the end of the MCT dataset (2001) to see if the current findings still hold. In addition, further disaggregation of the dataset should include not only the type of force being employed but also the level of force. A deployment of 20,000 troops is clearly different from the mobilization of a few platoons, but both are classified as land signals. This data conflates these distinctions, therefore inhibiting out ability to distinguish whether theories that predict the need for higher military allocations for signaling to decrease the probability of war and increase the probability of concessions. 


\section{References}

[1] Betts, Richard K. "Pick Your Poison." Foreign Affairs. 5 Sept. 2013 <http://www.foreignaffairs.com/articles/139906/richard-k-betts/pick-your-poison>.

[2] Blechman, Barry M., and Stephen S. Kaplan. 1978. Force without war: US armed forces as a political instrument. Washington, DC: Brookings Institution.

[3] Cable, James. 1971. Gunboat Diplomacy: Political Applications of Limited Naval Force. Chatto and Windus for the Institute for Strategic Studies.

[4] A crisis mismanaged : Obama's failed Syria policy : hearing before the Subcommittee on the Middle East and North Africa of the Committee on Foreign Affairs, House of Representatives, One Hundred Thirteenth Congress, first session, June 5, 2013.

[5] Downes, Alexander B., and Todd S. Sechser. 2012. "The Illusion of Democratic Credibility." International Organization 66(3): 457-89.

[6] Fearon, James. 1992. "Threats to Use Force: The Role of Costly Signals in Internatinal Crises." Ph.D. diss., University of California, Berkely.

[7] Fearon, James D. 1994a "Domestic political audiences and the escalation of international disputes." American Political Science Review 88(3): 577-592.

[8] Fearon, James D. 1994b. "Signaling Versus the Balance of Power and Interests: An Empirical Test of a Crisis Bargaining Model." Journal of Conflict Resolution 38(2): 236269.

[9] Fearon, James D. 1995. "Rationalist explanations for war." International Organization 49(3): 379-379.

[10] Fearon, James D. 1997 "Signaling Foreign Policy Interests Tying Hands versus Sinking Costs." Journal of Conflict Resolution 41(1): 68-90.

[11] Fuhrmann, Matthew, and Todd S. Sechser. 2014. "Signaling Alliance Commitments: Hand-Tying and Sunk Costs in Extended Nuclear Deterrence." American Journal of Political Science (forthcoming).

[12] Glaser, Charles L. 1994. "Realists as optimists: Cooperation as self-help." International Security 19.(3): 50-90.

[13] Jackson, David. "Obama tied down by Syria red line comment." USA Today. May 6, 2013 <http://www.usatoday.com/story/theoval/2013/05/06/obama-syria-red-line-newyork-times-story $/ 2138249 />$.

[14] Jervis, Robert. 1989. The logic of images in international relations. Columbia University Press.

[15] Jervis, Robert. 1978. "Cooperation under the Security Dilemma." World Politics 30(2): $167-214$. 
[16] Jervis, Robert. 1989. The Logic of the Images in International Relations. Columbia University Press.

[17] Kydd, Andrew H. 2005. Trust and mistrust in international relations. Princeton University Press.

[18] Lai, Brian. 2004. "The effects of different types of military mobilization on the outcome of international crises." Journal of Conflict Resolution 48(2): 211-229.

[19] Leeds, Brett Ashley, Jeffrey M. Ritter, Sara McLaughlin Mitchell, and Andrew G. Long. 2002. "Alliance Treaty Obligations and Provisions, 1815-1944." International Interactions 28(3): $237-60$.

[20] Lektzian, David J., and Christopher M. Sprecher. 2007. "Sanctions, signals, and militarized conflict." American Journal of Political Science 51(2): 415-431.

[21] Mandel, Robert. 1986. "The effectiveness of gunboat diplomacy." International Studies Quarterly 30(1):59-76.

[22] Marshall, Monty G., Keith Jaggers, and Ted Robert Gurr. 2013. "Polity IV Project: Political Regime Characteristics and Transitions, 1800-2012." <http://www.systemicpeace.org/polity4.htm>.

[23] Maoz, Zeev. 2005. Dyadic MID Dataset, Version 2.0.

[24] Miklasqewski, Jim, Courtney Kube, and Keir Simmons. "Obama on Syria: 'I have not yet made a decision." NBC News. 12 August 2013. <http://www.nbcnews.com/news/world/obama-syria-i-have-not-made-decisionv20227083>.

[25] Morgan, S. L., and C. Winship. 2007. Counterfactuals and causal inference: Methods and principles for social research. Cambridge University Press.

[26] Botter, Philip, and Matthew Baum. 2014. "Looking for Audience Costs in all the Wrong Places: Electoral Institutions, Media Access and Democratic Constraint." Journal of Politics (forthcoming).

[27] Powell, Robert. 1999. In the shadow of power: States and strategies in international politics. Princeton University Press.

[28] Press, Daryl G. 2005. Calculating Credibility: How Leaders Assess Military Threats. Ithaca, N.Y.: Cornell University Press.

[29] Sartori, Anne E. 2002. "The Might of the Pen: A Reputational Theory of Communication in International Disputes." International Organization 56(1): 121149.

[30] —. 2005. Deterrence by Diplomacy. Princeton: Princeton University Press.

[31] Schelling, Thomas C. 1960. The Strategy of Conflict. Cambridge, Mass.: Harvard University Press 
[32] - 1966. Arms and influence. New Haven: Yale University Press.

[33] Schultz, Kenneth A. 2001. Democracy and Coercive Diplomacy. New York: Cambridge University Press.

[34] Sechser, Todd S. 2010. "Goliaths Curse: Coercive Threats and Asymmetric Power." International Organization 64(4): 627-60.

[35] — 2011. "Militarized Compellent Threats, 1918-2001." Conflict Management and Peace Science 28(4): 377-401.

[36] Singer, J. David, Stuart Bremer, and John Stuckey. 1972. "Capability Distribution, Uncertainty, and Major Power War, 1820-1965." in Bruce Russett (ed) Peace, War, and Numbers, Beverly Hills: Sage, 19-48.

[37] Slantchev, Branislav L. "Military coercion in interstate crises." 2005. American Political Science Review 99(4): 533-547.

[38] Slantchev, Branislav L. 2011. Military Threats: The Costs of Coercion and the Price of Peace. Cambridge University Press.

[39] Snyder, Jack, and Erica Borghard. 2011. "The cost of empty threats: A penny, not a pound." American Political Science Review, 105(3): 437-456.

[40] Stinnett, Douglas M., Jaroslav Tir, Philip Schafer, Paul F. Diehl, and Charles Gochman. 2002. "The Correlates of War Project Direct Contiguity Data, Version 3." Conflict Mangagement and Peace Science 19(2):58-66.

[41] "Syria crisis: Obama warns Assad over chemical plan." BBC News. 14 September 2013 <http://www.bbc.com/news/world-middle-east-24098159>.

[42] Tomz, M. 2007. "Domestic audience costs in international relations: An experimental approach." International Organization, 61(4), 821-840.

[43] Trachtenberg, Marc. 2012. "Audience Costs: An Historical Analysis." Security Studies 21(1): 342 .

[44] Trager, R. F. 2010. "Diplomatic calculus in anarchy: How communication matters." American Political Science Review, 104(02), 347-368. 